\title{
ANALISIS PETROFISIKA DAN PENYEBAB LOW RESISTIVITY RESERVOIR ZONE BERDASARKAN DATA LOG, SEM, XRD DAN PETROGRAFI PADA LAPANGAN $X$ SUMATERA SELATAN
}

\author{
Rita Aprilia $^{1 *}$, Ordas Dewanto ${ }^{1}$, Karyanto ${ }^{1}$, Aldis Ramadhan ${ }^{2}$ \\ ${ }^{1}$ Teknik Geofisika, Fakultas Teknik Universitas Lampung \\ ${ }^{2}$ PT. PERTAMINA EP \\ J1 Prof. Dr. Sumantri Brojonegoro No.1 Bandar Lampung 35145 \\ Jurusan Teknik Geofisika, FT UNILA \\ *Email: aprilia2702@gmail.com
}

\begin{abstract}
ABSTRAK
Zona reservoar hidrokarbon yang berada pada Low Resistivity merupakan suatu lapisan minyak gas yang khusus dan tersembunyi yang selalu salah dalam menilai sebagai lapisan air dikarenakan asal geologi yang kompleks dan keterbatasan dari log resistivitas dalam mengidentifikasi hidrokarbon. Hadirnya lempung dalam sebuah reservoar akan menurunkan nilai resistivitas dan menaikkan nilai saturasi, sehingga dapat menyebabkan hasil analisis menjadi pesimis dalam identifikasi hidrokarbon. Maka dalam hal itu perlu dilakukannya analisis terhadap data core pada daerah penelitian agar dapat diketahui penyebab dari Low Reseistivity pada zona reservoar yang mungkin memiliki kandungan hidrokarkbon. Zona reservoar yang memiliki nilai resistivitas rendah berada pada kedalam 1572-1577 $\mathrm{mD}$. Pada zona ini, memiliki nilai resistivitas yang rendah berada diantara 2.7- $4.4 \mathrm{ohm}-\mathrm{m}$, dengan nilai saturasi air berada diantara 47\%-74\% yang menyebabkan pada zona reservoar Low Resistivity berada diantara hidrokarbon dan zona reservoar air. Kemudian pada zona penelitian ini, Low Resistivity juga disebabkan karena hadirnya serpihan jenis Lamination Clay yang terdiri dari beberapa jenis Clay yang dapat menyebabkan zona reservoar berada pada nilai resistivitas rendah. Jenis Clay ini berupa mineral Kaolite 20\%, Illite 4\%, dan Chlorite 4\% serta hadirnya mineral lain sebagai pendukung resistivitas rendah yaitu Quartz 60\%, Plagioclase 9\% dan Calcite 3\% sebagai mineral konduktif.
\end{abstract}

\begin{abstract}
Hydrocarbon reservoir zone located on Low Resistivity is a typical and hidden oil and gas layer which always wrong in assessing as a water layer due to the complex geological origin and resistivity log limitation in identifying hydrocarbon. Presence of shale in a reservoir will decreasing resistivity value and increasing saturation value, so it can cause the results of the analysis to be pessimistic in the identification of hydrocarbons. In that case need to do analysis to core data on research area in order to know the cause of Low Resistivity on reservoir zone that having a probability of hydrocarbon content. Reservoir zone that has low resistivity value is at depth $1572-1577 \mathrm{mD}$. In this zone, it has a low resistivity value around 2.7- $4.4 \mathrm{ohm}-\mathrm{m}$, with water saturation value around $47 \%-74 \%$ which causes on Low Resistivity reservoir zone to be between hydrocarbons and water reservoir zone. Then, on this research, Low Resistivity is also caused by Lamination Clay of shale type presence which consists of several types of Clay which can cause reservoir zone is at low resistivity value. This Clay type consist of Kaolite $20 \%$, Illite 4\%, and Chlorite $4 \%$ minerals as well as the presence of other minerals as proponent of low resistivity that is Quartz $60 \%$, Plagioclase $9 \%$ and Calcite $3 \%$ as conductive minerals.
\end{abstract}

Keyword: Mud log, Low Resistivity, X-Dry Difraction, SEM, Petrography 


\section{PENDAHULUAN}

Industri MIGAS di Indonesia masih memegang peranan penting dalam ekonomi negara. Dalam beberapa tahun belakangan industri MIGAS di Indonesia mengalami penurunan karena berkurangnya jumlah cadangan MIGAS yang ada. Oleh sebab itu, eksplorasi secara berkelanjutan dan terus menerus diperlukan untuk menambah kembali cadangan yang ada. Kegiatan eksplorasi minyak bumi merupakan tahapan penting dalam industri MIGAS dimana cadangan yang baru ditemukan. Salah satu metode yang bisa digunakan yaitu metode well logging Pada kasus penelian ini, penulis fokus pada Low Resisitivity Reservoir yang digunakan untuk menemukan cadangan hidrokarbon pada daerah penelitian. Low Resistivity disebabkan karena beberapa faktor yang mempengaruhinya yaitu, keberadaan mineral berat yang bersifat konduktif, shaly sand reservoir, fresh water formation, dan microporosity.

Metode well logging ini merekam respon dari alat log yang dimasukan ke dalam sumur karena perbedaan sifat fisik dan fluida batuan. Respon tersebut direkam secara terus menerus dalam sebuah kurva. Kurva ini mengandung informasi mengenai keadaan formasi batuan di bawah suatu sumur baik itu jenis litologi maupun fluida. Hasil well logging yang berupa kurva tersebut memerlukan teknik interpretasi untuk menginterpretasi kondisi bawah permukaan, menentukan lapisan yang mengandung hidrokarbon, dan zona penyebaran hidrokarbon.

Analisis petrofisika terdiri dari dua tahap, yang pertama adalah interpretasi kualitatif untuk menentukan zona prospek dan yang kedua adalah interpretasi kuantitatif. Interpretasi kuantitatif bertujuan untuk menentukan nilai-nilai parameter petrofisika batuan seperti volume serpih, porositas, permeabilitas, saturasi air, dan saturasi hidrokarbon. Nilai-nilai tadi berguna dalam pengambilan keputusan selanjutnya yang menentukan nasib suatu sumur. Nilai-nilai parameter ini dijadikan sebagai dasar dalam pembuatan net-pay suatu zona yang merupakan aset bagi perusahaan. Setelah diketemukan jumlah cadangan hidrokarbon dalam suatu lapisan dan dianggap ekonomis kegiatan dilanjutkan dengan eksploitasi. Kegiatan ini diharapkan dapat mengembangkan zona hidrokarbon lebih luas.

Penelitian ini dilakukan pada lapangan $\mathrm{X}$, Sumatera Selatan. Cekungan Sumatera Selatan merupakan salah satu cekungan sedimen yang sampai saat ini masih menyumbang cadangan minyak dan gas bumi di Indonesia. Cekungan ini terletak di sebelah timur dari Pegunungan Barisan dan memanjang sampai ke paparan Sunda di tenggara. Reservoir utama pada cekungan ini yaitu batupasir Formasi Talang Akar, batuan karbonat Formasi Baturaja, dan batupasir Air Benakat. Meskipun sudah banyak minyak yang dihasilkan, cekungan ini masih menarik untuk dieksplorasi.

Tujuan dalam penelitian ini adalah sebagai berikut:

1. Menentukan zona menarik dengan nilai Low Resistivity yang terlewatkan pada saat interpetasi awal pada lapangan $\mathrm{X}$

2. Menentukan penyebab Low Resistivity serta kandungan mineral pada zona Low Resistivity reservoar.

3. Analisis data petrofisika dan penyebab Low Resistivity pada zona penelitian.

\section{TINJAUAN PUSTAKA}

Penelitian ini berada pada Lapangan X terletak di Sumatera Selatan dengan arah NESW dan terletak pada daerah tinggian. Pada lapangan $\mathrm{X}$ merupakan Cekungan Busur Belakang (Back Arc Basin) yang terbentuk akibat interaksi antara Lempeng HindiaAustralia dengan Lempeng Mikro Sunda, sehingga mengakibat proses tektonik pada daerah penelitian.

Proses tektonik dipengaruhi oleh ketiga fase tektonik cekungan, yaitu:

a. Syn-Rift Megasequence

Pada fase ini terjadi gerakan ekstensional dari masa Eosen sampai dengan Oligosen Awal yang menyebabkan terbentuknya Rift Basin sepanjang batas selatan dari Sunda Self.

b. Post-Rift Megasequenc

Fase ini terjadi pada masa Oligosen 
sampai dengan Miosen. Pada fase relatife stabil bahkan diam.

c. Inversi Megasequence

Fase ini terjadi pada masa Pliosen sampai dengan Pleistosen, dimana pada fase ini cekungan aktif kembali sehingga menyebabkan terbentuknya antiklinantiklin sebagai perangkap hidrokarbon.

\section{TEORI DASAR}

\section{A. Metode Well Logging}

Logging merupakan metode pengukuran besaran-besaran fisik batuan terhadap kedalaman lubang bor. Sesuai dengan tujuan logging yaitu menentukan besaran-besaran fisik batuan maka dasar dari logging itu sendiri adalah sifat-sifat fisik atau petrofisik dari batuan. Well logging dapat dilakukan dengan dua cara dan bertahap yaitu dengan openhole logging dan casedhole logging. Terdapat beberapa Jenis log yang digunakan dalam eksplorasi geofisika khususnya dalam penelitian ini, yaitu:

\section{Log Gamma Ray}

Gamma Ray Log adalah metoda untuk mengukur radiasi sinar gamma yang dihasilkan oleh unsu-unsur radioaktif yang terdapat dalam lapisan batuan di sepanjang lubang bor. Radioaktivitas GR log berasal dari 3 unsur radioaktif yang ada dalam batuan yaitu Uranium (U), Potasium (P), Thorium (Th) yang secara kontinyu memancarkan Gamma Ray dalam bentuk pulsa-pulsa energi radiasi tinggi. Kegunaan dari log Gamma Ray adalah:

a. Evaluasi kandungan serpih/ shale (Vsh)

b. Evaluasi bijih mineral radioaktif

c. Evaluasi lapisan mineral yang bukan radioaktif

d. Korelasi log pada sumur berselubung (Harsono, 2007).

\section{Log Densitas}

Log densitas adalah rekaman densitas keseluruhan (bulk density) batuan. Bulk density ini mencakup densitas matrix dan fluida di dalamnya. Prinsip kerja log densitas yaitu suatu sumber radioaktif dari alat pengukur dipancarkan sinar gamma dengan intensitas energi tertentu menembus formasi/batuan.

\section{Log Neutron}

Log neutron adalah rekaman reaksi formasi batuan terhadap bombardir neutron berkecapatan tinggi. Log neutron ini merekam jumlah neutron yang tertangkap kembali oleh detektor sehingga berhubungan dengan indeks hidrogen formasi. Porositas dari log ini berhubungan dengan indeks hidrogen batuan. Jika dalam batuan terdapat banyak air, maka porositas akan berkurang dan nilai kurva log neutron akan tinggi. Jika terdapat porositas yang banyak di dalam batuan nilai kurva log neutron batuan menjadi rendah. Porositas dari log ini dinyatakan dalam Neutron Porosity Unit. Respon alat logging neutron mencerminkan banyaknya atom hidrogen di dalam formasi batuan. Karena minyak dan air mempunyai jumlah hidrogen per unit volume yang hampir sama, maka log neutron akan memberikan respon porositas fluida dalam formasi bersih.

\section{Log Resistivitas}

Resistivity log adalah metoda untuk mengukur sifat batuan dan fluida pori seperti minyak, air dan gas disepanjang lubang bor dengan mengukur sifat tahanan kelistrikannya. Besaran resistivitas batuan dideskripsikan dengan Ohm Meter, dan biasanya dibuat dalam skala logarithmic dengan nilai antara 0,2 sampai dengan 2000 Ohm Meter. Metoda resistivity logging ini dilakukan karena pada hakekatnya batuan, fluida dan hidrokarbon di dalam bumi memiliki nilai resistivitas tertentu.

\section{B. Interpretasi Formasi Pasir Serpih (Shaly Sand)}

Shaly Sand Formation adalah suatu istilah yang digunakan untuk menunjukkan bahwa suatu formasi tidak hanya mengandung pasir saja, tetapi terdapat shale pada kandungan pasirnya. Pada shaly-sand formation perhitungan nilai saturasi air yang akan dilakukan cenderung lebih sulit jika dibandingkan dengan yang dilakukan pada clean formation. Hal ini terjadi karena shale yang hadir dalam suatu formasi dapat menyebabkan perubahan pembacaan nilai 
pada saat dilakukan pengukuran dengan menggunakan logging sehingga perlu dilakukan koreksi. Formasi pasir serpihan (shaly formation) ini pada umumnya berupa mineral lempung yang berupa kaolinit, illit atau smektit. Kehadiran shale pada suatu reservoar dapat berdampak pada beberapa hal yaitu, mengurangi porositas efektif, pada umumnya berkurang banyak, menurunkan nilai permeabilitas, terkadang turun drastis dan merubah nilai resistivitas, seperti yang ditunjukkan pada Gambar 1.

\section{METODOLOGI PENELITIAN}

\section{A. Lokasi dan Waktu Penelitian}

Penelitian dilaksanakan di Pertamina EP Fungsi Eksplorasi, Lt. 16, Jakarta Selatan dengan waktu pelaksanaan periode September 2017 sampai dengan November 2017. Lalu dilanjutkan di Jurusan Teknik Geofisika Universitas Lampung s/d Ujian Komprehensif.

\section{B. Alat dan Bahan Penelitian}

Alat dan bahan yang digunakan pada penelitian ini adalah sebagai berikut:

1. Laptop

2. Software Interactive Petrophysics $3.5 \mathrm{v}$

3. Software Microsoft Excel

4. Data Sumur (Log). LAS

5. Data Mudlog

6. Data DST

7. Data Routine Core Analysis

8. Data Analisis Batuan (Petrography, XRD \& SEM )

\section{Prosedur Penelitian}

\section{Inventory Data}

Pada tahap ini data yang telah didapatkan diinventarisasikan

\section{Loading Data}

Melakukan penginputan data pada data log Gamma Ray, log Resistivitas dan log Porositas yang terbagi atas neutron log porosity (NPHI) dan density porosity (RHOB). Kemudian dilakukan zonasi yang bertujuan untuk menentukan lapisan-lapisan yang terdapat pada bawah permukaan.
Setelah dilakukan zonasi dilakukan perhitungan pada porositas (PHIE), kandungan lempung (Vclgr) dan saturasi air $(\mathrm{Sw})$ dengan menggunakan persamaan Indonsian dan perhitungan porositas (PHIE). Setelah itu dilakukan Cut-off yang bertujuan untuk mengetahui lapisan-lapisan prospek. Kemudian langkah yang terakhir dilakukan Lumping, yang bertujuan untuk mengetahui nilai dari porositas (PHIE), kandungan lempung (Vclgr) dan saturasi air $(\mathrm{Sw})$.

\section{Analisis Data}

Analisis data ini dilakukan pada data sumur RAW-01 yang terfokuskan pada formasi Gumai. Analisis data ini dilakukan untuk mengetahui zona-zona yang berpotensi hidrokarbon namun berada pada Low Resistivity dan juga untuk mengetahui penyebab Low Resistivity serta mengetahui kandungan mineral-mineral yang ada pada zona reservoar Low Resistivity.

\section{HASIL DAN PEMBAHASAN}

\section{A. Indikasi dan Penyebab Low Resistivity Zone}

Sebelum melakukan penentuan Low Resistivity Zone, maka diperlukan indikasi zona Low Resistivity terlebih dahulu. Proses indikasi ini menggunakan data Mud Log sebagai acuan dalam tahap indikasi zona prospek namun berada pada nilai resistivitas yang rendah. Data Mudlog digunakan untuk mengidentifikasi tipe formasi dan litologi yang dibor, mengidentifikasi zona yang porous \& permeabel, mengetahui batas kedalaman pengeboran akhir dan memastikan keberadaan hidrokarbon sampai pada tahap membedakan jenis hidrokarbon tersebut apakah minyak atau gas. Kemudian dilakukan kalibrasi terhadap data Mud Log dan Wireline Log pada zona yang telah ditentukan, agar dari kedua data dalam satu zona ini menjadi singkron dan valid. Dari hasil validasi antara hasil perhitungan dengan data core akan menunjukkan karaktristik dari reservoar batupasir dengan harga resistivitas rendah dan juga dapat 
diketahui pengontrol turunnya harga reristivitas dalam lapisan batupasir yang mengandung hidrokarbon.

Berikut merupakan zona-zona indikasi Low Resistivity pada penelitian, yaitu zona 1 dan zona 2. Indikasi Low Resistivity pada zona 1 seperti pada Gambar 2, berada pada kedalaman 1572-1577 measured deep. Pada zona ini dilakukan kalibrasi antara data Mud Log dengan data Wireline Log zona 1 agar didapatkan data yang valid.

Dari data Mud Log, pada zona 1 terdapat litologi Sandstone, Siltstone dan Shale namun yang lebih mendomiunasi adalah litologi Sandstone, kemudian terdapatnya Gas Cromatograph yaitu C2nC4 yang menandakan hidrokarbon dengan total gas sebrsar 63.45 unit dan begron gasnya 8 sampai 12 unit gas. Lalu dari deskripsi cutting atau swc terdapat trace serta dari Wireline Log menunjukkan nilai Gamma Ray sebagai Shaly Sand, terdapatnya cross over antara Log Neutron dan Densitas, serta nilai resistivitas yang menunjukan rendah sebesar $4.4 \mathrm{ohm}$ meter.

Setelah dilakukan tahapan indikasi zona Low Resistivity, maka dilanjutkan dengan mengidentifikasi penyebab Low Resistivity pada zona 1 dengan analisis data core menggunakan data SEM pada Gambar 3, Petrograpfi pada Gambar 5 dan XRD pada

\section{Gambar 4.}

Dari analisis ketiga data diatas maka didapatkan kesimpulan bahwa Low Resistivity pada zona 1 disebabkan karena adanya mineral Clay, Conductive Mineral serta adanya Micrporosity. Dimana pada zona ini merupakan litologi Sandstone dgn klasifikasi Suberkose, yaitu Sandstone tersusun dari Quarsa dan Feldspar, dimana kandungan mineral Quarsa nya lebih dominan. Pada zona 1 ini memiliki kandungan butiran Quarsa sebanyak 60\%, terdapatnya Secondary Porosity yang disebabkan oleh pnghancuran mineral Calcite sebanyak 3\% sebagai Conductive Mineral. Kemudian teerdapatnya mineral jenis mineral Clay yaitu Kaolinite sbanyak $20 \%$, Illite $4 \%$, Chlorite $4 \%$.

Indikasi Low Resistivity pada zona 2 seperti pada Gambar 6, berada pada kedalaman 1718-1720 measured deep. Pada zona ini dilakukan kalibrasi antara data Mud
Log dan Wireline Log juga, sehingga didapatkan hasil indikasi dari Low Resistivity Zone sebagai berikut, dari data Mud Log bahwa pada zona 2 terdapat litologi Sandstone, Siltstone dan Shale namun yang lebih mendominasi adalah litologi Sandstone, kemudian terdapatnya Gas Cromatograph yaitu $\mathrm{C} 1-\mathrm{nC} 4$ yang menandakan hidrokarbon dengan total gas sebrsar 9.07 unit gas dan begron gasnya 1.5 sampai 4 unit gas serta terdapatnya oil show pada kedalam 1720 sampai 1734 measured deep. Lalu dari deskripsi cutting atau swc terdapat trace atau oil show serta dari Wireline Log menunjukkan nilai Gamma Ray sebagai Shaly Sand, terdapatnya cross over antara Log Neutron dan Densitas, serta nilai resistivitas yang menunjukan rendah sebesar $4.5 \mathrm{ohm}$ meter.

Kemudian dilakukan analisis data core terhadap zona 2 berdasarkan data SEM pada Gambar 7, Petrograpfi pada Gambar 9 dan XRD pada Gambar 8. Dari analisis ketiga data core, sehingga didapatkan kesimpulan bahwa Low Resistivity ini disebabkan karena adanya mineral Clay, Conductive Mineral serta adanya micrporosity yang terbentuk pada saat sementasi. Lalu pada zona 2 ini merupakan zona dengan litologi Sandstone klasifikasi Suberkose, yaitu Sandstone yang tersusun dari Quarsa dan Feldspar, dimana kandungan mineral Quarsa nya lebih dominan. Perbedaan kandungan mineral pada kedua zona ini, adalah pada zona 2 memiliki kandungan butiran Quarsa sebanyak 54\%, terdapatnya Secondary Porosity yang disebabkan oleh pnghancuran mineral Calcite sebanyak 26\% sebagai Conductive Mineral. Kemudian terdapatnya mineral jenis mineral Clay yaitu Kaolinite sebanyak 5\%, Illite 5\%.

\section{B. Analisis Data Petrofisika}

Pada penelitian ini analisis petrofisika sangat penting dilakukan, karena analisis petrofisika merupakan salah satu proses yang penting dalam usaha untuk menentukan karakteristik suatu reservoar. Melalui analisis petrofisika dapat diketahui zona reservoar, jenis litologi, identifikasi prospek hidrokarbon, porositas, volume shale dan saturasi air. Penelitian ini menggunakan software interactive petrophysics v3.5 dalam pengolahan datanya. 
Dalam analisis data petrofisika ini, sebelum dilakukan perhitungan-perhitungan parameter petrofisika dengan menggunakan software Interactive Petrophysics v3.5. Hal yang pertama dilakukan adalah dengan menampilkan kurva log triple combo terhadap data.Las penelitian, setelah tertampil output dari log triple combo maka diatur terhadap parameter log yang akan ditampilkan dan digunakan. Dalam penampilan pada kolom pertama hanya paramter log gamma ray yang ditampilkan. Kemudian pada kolom kedua parameter log yang ditampilkan dan digunakan adanya log resistivity dan pada kolom ketiga parameter log yang ditampilkan dan digunakan parameter log density dan log neutron porosity.

Setelah dilakukan pengaturan terhadap tampilan parameter kurva log, maka dilanjutkan dengan melakukan zonasi terhadap kurva log berdasarkan data formasi, kemudian melakukan pengaturan skala log terhadap parameter-parameter log agar kurva yang tertampilkan menjadi lebih informatif dan juga efisien dalam proses interpretasi kurva log yang akan dilakukan nanti. Dari hasil zonasi berdasarkan formasi yang dilakukan, maka dilanjutkan dengan proses perhitungan clay volume sehingga didapatkan perhitungan kandungan lempung pada daerah penelitian. berdasarkan perhitungan clay volume, terlihat pada formasi penelitian dengan interval kedalaman 1546-1935 meter terdapat litologi shale yang banyak. Maka dari itu perlu dilakukan determinasi Volume Clay ini untuk menderterminasi nilai clean sand dan shale baseline.

Kemudian dilakukan perhitungan porositas, permeabilitas, resistivitas air, yang didapatkan sebesar 0,3 ohm-meter. Lalu perhitungan nilai resistivitas clay, perhitungan nilai saturasi air yang didapatkan pada zona 1 sebesar $74 \%$ dan pada zona 2 sebesar $47 \%$. Setelah didapatkan output dari perhitungan Saturation Water, maka dilanjutkan dengan mengkalibrasi dengan data Mud Log pada interval yang sama dengan zona 1 dan zona 2 yang menandakan indikasi zona Low Resistivity. Jika hasil output dari perhitungan Saturation Water singkron dengan data Mud Log, maka dilanjutkan dengan proses perhitungan Cut-Off pada zona 1 dan zona 2 .

Pada penelitian ini, penentuan cut-off menggunakan metode crossplot antara Porositas Evektif dengan Vshale dan crossplot antara Porositas Evektif dengan Saturation Water menggunakan Microsoft Excell. Dari kedua crossplot inilah dapat dilihat persebaran data penelitian pada formasi Gumai dan dapat ditarik suatu ambang batas dari ketiga parameter tersebut yang akan dijadikan sebagai nilai cut-off untuk mendapatkan hasil Lumping. Adapun nilai cut-off dari Porositas Evektif (PHIE) sebesar 0,08 atau $8 \%$, nilai cut-off dari Volume Wet Clay (VWCL) sebesar 0,28 atau $28 \%$ dan nilai cut-off dari Saturation Water sebesar 0,75 atau $75 \%$.

Selanjutnya dilakukan proses Lumping, kemudian dilakukan suatu perbandingan terhadap hasil Lumping zona 1 dan zona 2 untuk mengetahui apakah zona yang telah diindikasikan sebagai zona Low Resistivity ini memiliki hidrokarbon dan dapat mengalirkan fluida hidrokarbon atau tidak. Dengan memasukkan nilai parametr cut-off yang sama terhadap zona 1 dan zona 2 yaitu nilai cut-off PHIE 0,08 atau 8\%, Sw 0,75 atau $75 \%$ dan VWCL 0,28 atau $28 \%$ maka didapatkan hasil Lumping yang berbeda pada kedua zona indikasi Low Resistivity tersebut. Pada zona 1 terdapat konten dari Reservoir Flag dan Pay Flag yang menunjukkan bahwa pada zona tersebut terdapat hidrokarbon yang dapat mengalir.

Zona ini memiliki ketebalan Net Res sebesar 3,89 meter. Sedangkan pada hasil Lumping zona 2 tidak adanya konten dari Reservoir Flag dan Pay Flag, sehingga menunjukkan pada zona 2 ini bukanlah zona yang prospek pada Low Resistivity. Sehingga, dari hasil Lumping yang didapatkan dari zona 1 dan zona 2 ini dapat disimpulkan bahwa zona Low Resistivity yang mengandung hidrokarbon dan dapat mengalirkan fluida merupakan zona 1 Low Resistivity yang berada pada interval 1572 1577 maesured deep $(\mathrm{mD})$.

\section{Analisis Low Resistivity Zone}

Dari hasil indikasi zona Low Resistivity dan juga dari analisis terhadap perhitungan petrofisika terhadap zona indikasi Low 
Resistivity, maka didapatkan satu zona yang memiliki nilai resistivitas rendah namun tetap bisa mengalirkan fluida yaitu berada pada kedalaman 1572-1577 measure deep $(\mathrm{mD})$ formasi Gumai. Berdasarkan analisis dara core yang dilakukan, bahwa pada zona penelitian tersebut merupakan zona Low Resistivity yang terdapat litologi Sandstone dengan klasifikasi Subarkose. Dimana Subarkose ini merupakan batupasir atau Sandstone yang tersusun dari mineral Quartz dan Feldspar dengan kandungan mineral Quartz lebih dominan sekitar 75\%. Kemudian dari data Mud Log dan data Wireline Log yang telah diidentifikasi juga menunjukkan bahwa pada kedalam 15721577 measure deep $(\mathrm{mD})$ ini merupakan zona yang memiliki nilai resistivitas rendah serta pada zona tersebut memiliki trace dari gas cromatograph $\mathrm{C} 2-\mathrm{nC} 4$ yang menunjukkan adanya hidrokarbon dalam zona Low Resistivity ini. Berikut merupakan zona yang menjadi zona terfokuskan dalam penelitian Low Resistivity Reservoir seperti yang terdapat pada Gambar 10.

Dari zona Low Resistivity ini didapatkan, maka dilanjutkan dengan menganilisis zona tersebut untuk diketahui penyebab dari zona hidrokarbon yang berada dalam Low Resistivity Reservoir Zone pada daerah penelitian. Data sumur penelitian ini didominasi dengan adanya kehadiran dari litologi Shaly Sand yang sangat mempengaruhi nilai resistivitas, dimana Low Resistivity Hydrocarbon Reservoir adalah suatu lapisan minyak gas yang khusus dan tersembunyi yang selalu salah dalam menilai sebagai lapisan air dikarenakan asal geologi yang kompleks dan keterbatasan dari log resistivitas dalam mengidentifikasi hal tersebut. Umumnya nilai resistivitas tinggi pada reservoar porous di interpretasikan sebagai Hydrocarbon bearing, dikarenakan hidrokarbon memiliki nilai resistivitas lebih tinggi dibandingkan dengan air. Pada umumnya batupasir yang bersih memiliki nilai resistivitas dengan range nilai diatas 10 ohm-m, namun pada log deep resistivity dalam low resistivity pay memiliki range nilai $0.5-5 \mathrm{ohmm}$.

Dalam penelitian ini meggunakan sebuah pendekatan, yaitu dengan mengetahui penyebab reservoar Low Resistivity sehingga dapat menentukan zona-zona produktif yang memiliki nilai resistivitas rendah (Low Resistivity Reservoir) di Lapangan RAW yang kurang diperhatikan pada saat awal eksplorasi. Pendekatan selanjutnya yaitu dengan melakukan koreksi terhadap nilai resistivitas air (Rw) yang mana akan mempengaruhi dalam perhitungan penentuan saturasi air $(\mathrm{Sw})$, sehingga didapatkan hasil perhitungan Sw yang tepat dan optimis. Kemudian dengan melakukan interpretasi ulang petrofisika dengan menggunakan parameterparameter dari data Routine Core Analysis, SEM, XRD dan Petrography.

Pada daerah penelitian, reservoar Low Resistivity disebabkan oleh batupasir atau sandstone dengan lapisan serpih yang berlapis atau Clay Lamination yang terdiri dari dari Clay Mineral (Kaolite dan Illite), butiran Detrital Quartz dan adanya Secodary Porosity. Lempung dalam lapisan serpih ini pada umumnya tipis dan terletak berselangseling dengan pasir dan lapisan Clay Lamination ini juga berasal dari rombakan batuan.

Kemudian Low Resistivity pada daerah penelitian ini disebabkan juga oleh adanya Microporosity tersebar di dalam batuan yang terbentuk pada saat proses sedimentasi berlangsung, dan Low Resistivity ini disebabkan karena adanya pengaruh dari Conductive Mineral (iron-rich mineral) seperti mineral Pyrite, Siderite dan Calcite. Cara untuk mengetahui jenih lapisan serpih yang menyebabkan Low Resistivity dilakukan crossplot seperti pada Gambar 11.

Dari hasil crossplot yang dilakukan terhadap data Volume Wet Clay dan data Total Porosity pada zona Low Resistivity yang berada pada interval 1572-1577 measure deep $(\mathrm{mD})$ formasi Gumai ini berjenis Lamination Clay karena dilihat dari besaran nilai $\mathrm{V}$-shale sebesar $1 \%$ dan PHIT sebesar $15-20 \%$ yang ditunjukkan pada Gambar 5 diatas. Dimana Lamination Clay ini merupakan serpih yang berlapis tipis yang terletak berselang-seling dengan pasir, dan lapisan serpih ini berasal dari hasil rombakan batuan. Kemudian, pada zona Low Resistivity ini mengandung beberapa jenis mineral lain dan juga mineral Clay yang menjadi salah satu penyebab dari resistivitas 
rendah.

Dari hasil histogram pada Gambar 12, terhadap zona Low Resistivitas yang berada pada interval 1572-1577 measure deep (mD), maka dapat dilihat bahwa pada zona tersebut memiliki beberapa kandungan mineral yang dapat menybabkan zona penelitian berada pada zona resistivitas yang rendah. Dari histogram diatas pada zona Low Resistivity memiliki kandungan mineral Quartz sebanyak 60\%. Dimana mineral Quartz ini merupakan salah satu mineral yang umumnya bisa ditemukan di kerak kontinen bumi. Mineral ini memiliki struktur kristal heksagonal yang terbuat dari silika trigonal terkristalisasi. Kemudian terdapatnya Plagioclase sebanyak 9\% dalam batuan daerah penelitian, dimana mineral ini merupakan mineral yang termasuk ke dalam kelompok Feldspar. Dalam reaksi Bowen, Plagioclase berada pada seri kontinyu. Lalu terdapatnya mineral Calcite sebanyak 3\%, mineral Calcite merupakan minesral karbonat dan polimorf kalsium karbonat $\left(\mathrm{CaCO}_{3}\right)$ paling labil. Dalam hal penyebab Low Resistivity Zone mineral Calcite ini merupakan Conduktive Mineral yang dapat menyebabkan zona penelitian memiliki nilai resistivitas rendah. Selanjutnya terdapatnya mineral Clay sebanyak $28 \%$ yang terkandung dalam batuan zona daerah penelitian.

Mineral Clay ini merupakan mineral sekunder yang terbentuk karena proses pengerusakan atau pemecahan yang dikarenakan iklim dan alterasi air (Hidrous Alteration) pada suatu batuan induk dan mineral yang terkandung dalam batuan itu. Mineral Clay ini memiliki beberapa jenis Clay yaitu Smectite, Kaolinite, Illite dan Chlorite. Namun dalam zona penetian ini hanya terdapat kandungan Kaolinite, Illite dan Chlorite.

Dari histogram pada Gambar 13, maka dapat dilihat komposisi kandungan mineral Clay yang hadir pada batuan zona Low Resistivity. Pada zona penelitian ini terdapat mineral Kaolinite sebanyak 20\%. Dimana mineral Kaolinite ini terbentuk melalui proses pelapukan atau alterasi hidrotermal mineral Aluminosilikat. Karena itu, batuan yang kaya akan Feldspar ini biasanya akan mengalami pelapukan menjadi mineral Kaolinite. Mineral Kaolinite ini tidak bisa menahan air. Kemudian terdapatnya mineral Illite sebanyak 4\%, mineral ini terbentuk dari pelapukan batuan yang kaya akan $\mathrm{K}$ atau $\mathrm{Al}$ dibawah kondisi $\mathrm{pH}$ tinggi dan terdapatnya mineral Chlorite sebanyak 4\% juga, mineral Chlorite ini terdiri dari mineral-mineral yang kaya akan magnesium serta banyak ditemukan dalam batu serpih serta kelompok Chlorite ini juga banyak mengandung ion-ion besi.

Dari hasil analisis data Petrography, SEM dan XRD dan perhitungan terhadap parameter petrofisika yang dilakukan terhadap zona Low Resistivity ini, maka didapatkan hasil yang menyebabkan Low Resistivity pada zona penelitian. Jika dari perhitungan parameter petrofisika didapatkan pada zona penelitian memiliki nilai gamma ray berkisar antara 92 API sampai dengan 139 API dengan nilai permeabilitas sebesar 1 milli Darci. Kemudian didapatkan juga kualitas nilai prositas yang bervariasi diantara 13\%-19\% dengan nilai Saturation Water berada diantara $47 \%-74 \%$ yang dapat menyebabkan pada daerah Low Resistivity berada diantara hidrokarbon dan zona water reservoir. Hal yang paling utama, pada daerah penelitian ini terbukti benar adanya merupakan zona Low Resistivity, karena pada zona penelitian dengan interval 15721577 measure deep $(\mathrm{mD})$ ini memiliki nilai resistivitas yang rendah diantara 2,7-4,4 ohm-m yang disebabkan karena adanya kehadiran mineral Clay yang relatif banyak. Dari kandungan mineral Clay ini, tipe mineral jenis Kaolinite lebih mendominasi dengan persentase $20 \%$ dibandingkan dengan mineral Illite dan Chlorite.

\section{KESIMPULAN DAN SARAN}

\section{A. KESIMPULAN}

Setelah dilakukan interpretasi, maka didapatkan kesimpulan sebagai berikut:

1. Didapatkan zona Low Resistivity Reservoir pada kedalaman 1572-1577 meter sebagai zona menarik pada penelitian ini.

2. Adanya Low Resistivity Reservoir Zone ini disebabkan karena beberapa faktor yaitu, terdapatnya shaly sand reservoir, microporosity, conductive mineral dan terdapatnya jenis mineral clay dengan 
jumlah kaolite $20 \%$, illite $4 \%$ dan chlorite $4 \%$, serta kandungan mineral lain yaitu quartz $60 \%$, plagioclase $9 \%$ dan calcite $3 \%$.

3. Berdasarkan analisis petrofisika yang dilakukan pada zona Low Resistivity Reservoir, maka didapatkan nilai resistivitas rendah diantara 2.7-4.4 ohm-m, gamma ray diantara 92 API139 API, porositas evektif diantara $13 \%-19 \%$, saturasi air (Sw) diantara $47 \%-74 \%$ yang menyebabkan pada daerah Low Resistivity berada diantara Hidrocarbon dan zona Water Reservoir serta permeabilitas sebesar $1 \mathrm{mD}$.

\section{B. SARAN}

Dalam penelitian ini, perlu dibutuhkan data a,m, n dari data SCAL atau Special Core Analysis dan data Laboratorium Analysis agar perhitungan petrofisika bisa lebih tepat dan akurat. Kemudian dibutuhkan Structure Map daerah penelitian, agar bisa langsung diketahui jumlah cadangan $\mathrm{HC}$ pada zona Low Resistivity yang diidentifikasi

\section{UCAPAN TERIMA KASIH}

Penulis mengucapkan terima kasih kepada Bapak Aldis Ramadhan sebagai pembimbing penelitian di perusahaan, serta Bapak Dr. Ordas Dewanto S.Si., M.Si dan Bapak Karyanto, S.Si., M.T. yang telah membimbing dan memberikan dukungan terhadap penyelesaian penelitian ini.

\section{DAFTAR PUSTAKA}

Ariewijaya, A. 2007, Low Resistivity Low Contrast, Halliburton: Texas.

Asquith, George B., 1976, Basic Well Log Analysis for Geologist. American Association of Petroleum Geologist. Oklahoma.

Asquith, G. dan Krygowski, D. 2004, Basic Well Log Analysis : Second Edition. The American Association of Petroleum Geologists (AAPG): Oklahoma.
Crain, E. R., 2012, Crain Petrophysical Handbook, (www.spec2000.net diakses pada tanggal 9 november 2017, informasi yang diambil tentang water saturation).

Dewan, T.J.,: Essential of Modern OpenHole Log Interpretation, Pennwell Publishing Company, Tulsa-Oklahoma, USA, 1983.

Dewanto, O., 2009, Buku Ajar Well Logging. Universitas Lampung: Lampung.

Ellis, D.V. dan Singer, J.M., 2008, Well Logging for Earth Scientists: Second Edition. Springer: Dordrecht, The Netherlands.

Ginger, D., dan Fielding, K. 2005, The Petroleum Systems and Future Potential of The South Sumatera Basin. Proceeding Indonesian Petroleum Association (IPA), The $30^{\text {th }}$ Annual Convention \& Exhibition: Jakarta. Indonesia.

Harsono, A., 1997, Evaluasi Formasi dan Aplikasi Log: Edisi Revisi-8. Schlumberger Oil Services: Indonesia.

Harsono. A., 1997, Pengantar Evaluasi Log, Schlumberger Data Services, Jakarta.

Herdiansyah, F., Abdurrokhim, A., dan Syafri, I., 2016, Contribution Low Resistivity Zone Pada Reservoir Batupasir Formasi Cibulakan Atas Cekungan Jawa Barat Utara, Bulletin of Scientific, Teknik Geologi Universitas Padjajaran, Jakarta, Volume 14 No. 1.

Koesoemadinata, R.P., 1978, Geologi Minyak dan Gas Bumi Edisi kedua Jilid 1 dan 2. ITB : Bandung.

Kristanto, D., 1996, Basic Well Logging Analysis and Interpretation. Petroleum Engineering: Institut Teknologi Bandung.

Pertamina., 2013, Laporan Geological dan Laboratory Services Division. PT.GEOSERVICES, Indonesia (tidak dipublikasikan).

Pertamina. 2016, Laporan Internal PT. Pertamina EP. PT. Pertamina EP (Tidak 
diterbitkan).

POFD, DNF. 2006, POFD Limau Barat Tengah. PT. PERTAMINA EP Asset 2, Indonesia (tidak dipublikasikan).

Rider, M., 1996, The Geological Interpretation of Well Logs. John Wiley \& Sons, Inc., New York, USA.

Rider, M., 2002, The Geological Interpretation of Well Logs, $2^{\text {nd }}$ Edition, revised 2002. Scotland: Whittles Publishing.

Schlumberger. 1989. Log Interpretation Principles / Applications. Schlumberger Wireline \& Testing : Texas.
Serra P. A., Lopez C. K., Dorigueto R., dan Gananca F. F., 2009. Blood glucose and insulin levelsin patients with peripheralvestibular disease, Braz J Otorhinolaryngol. 75(5):701-5.

Triwibowo, B., 2010, Cut-off Porositas, Volume Shale, dan Saturasi Air untuk Perhitungan Netpay Sumur O Lapangan C Cekungan Sumatra Selatan, UPN, Jurnal Ilmiah MTG, Vol. 3, No. 2, Juli 2010.

Winardi, S., 2014. Quantitative Log Analysis. Depertement Of Geological Eng. Gadjah Mada University. 


\section{LAMPIRAN}
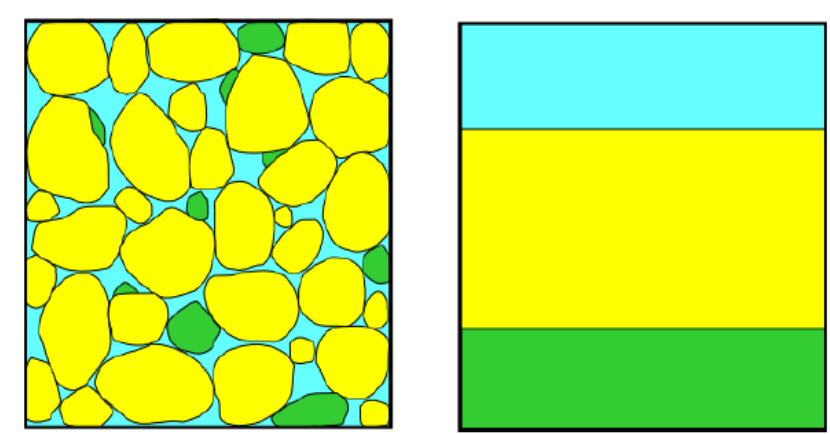

Fluids

Gambar 1. Model Reservoar Pasir Serpihan (Pertamina, 2016)

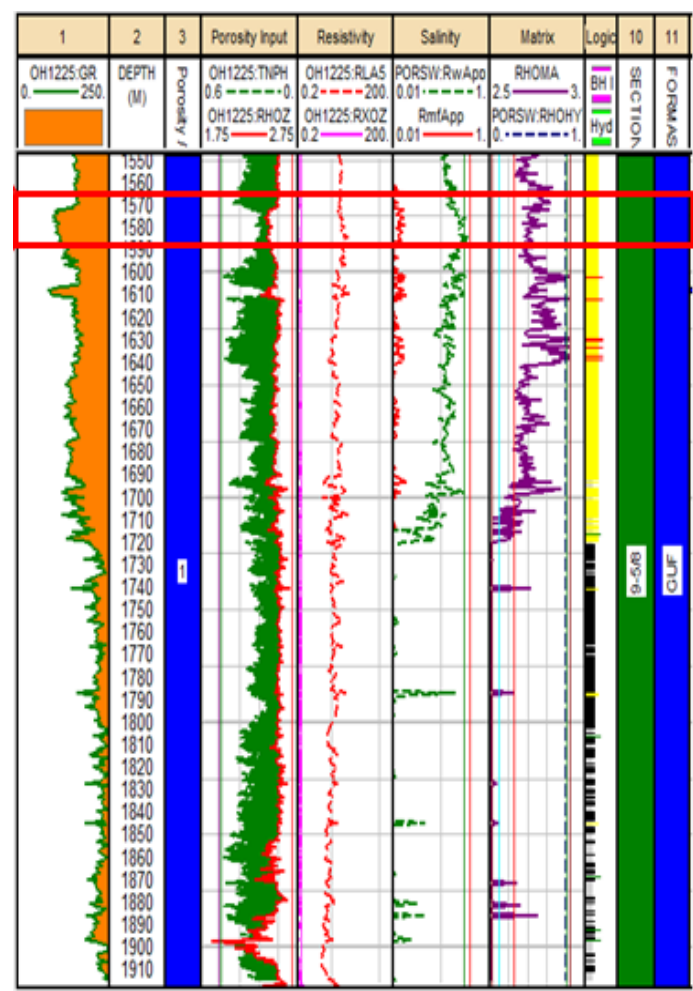

Gambar 2. Indikasi Low Resistivity Reservoir Zona 1

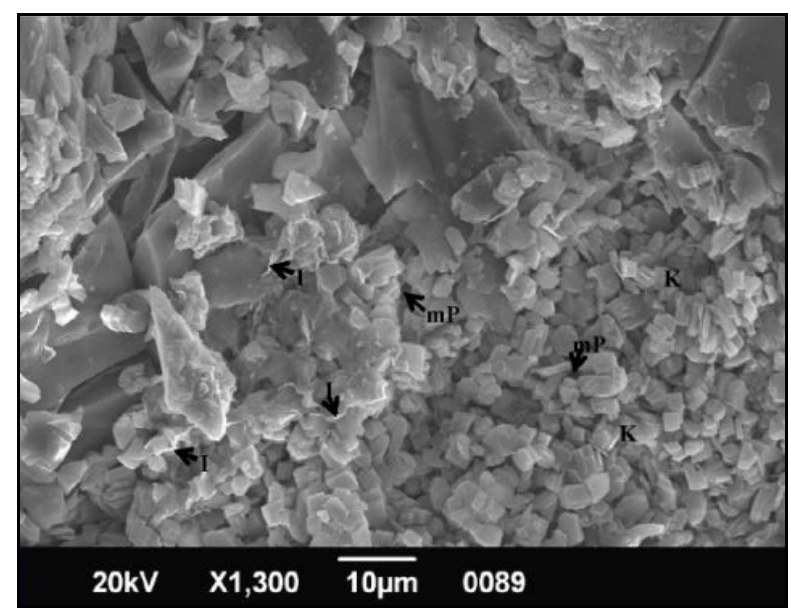

Gambar 3. Data SEM Zona 1 


\begin{tabular}{|c|c|c|c|}
\hline Other mineral [69\%] & $60 \%$ & Pyrite & $0 \%$ \\
\hline Quatz & $0 \%$ & Plagioclase & $9 \%$ \\
\hline K-feldspar & $0 \%$ & Gypsum & $0 \%$ \\
\hline Zeolite [Laumontite] & $3 \%$ & Dolomite & $0 \%$ \\
\hline Carbonate minerals [3\%] & $0 \%$ & & \\
\hline Calcite & & \\
\hline Siderite & $0 \%$ & Illite & $4 \%$ \\
\hline Clay minerals [28\%] & $20 \%$ & Chlorite & $4 \%$ \\
\hline Kaolinite & & & \\
\hline
\end{tabular}

Gambar 4. Data XRD Zona 1

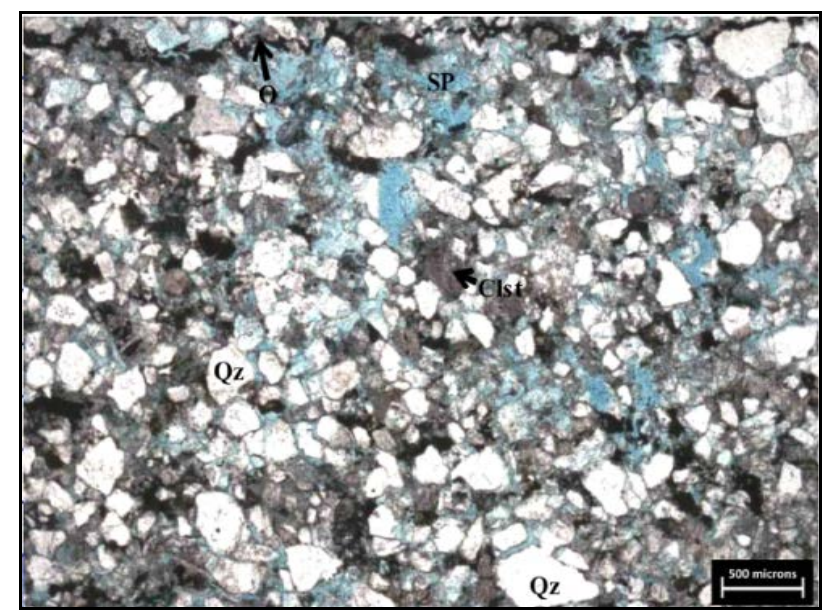

Gambar 5. Data Petrography Zona 1

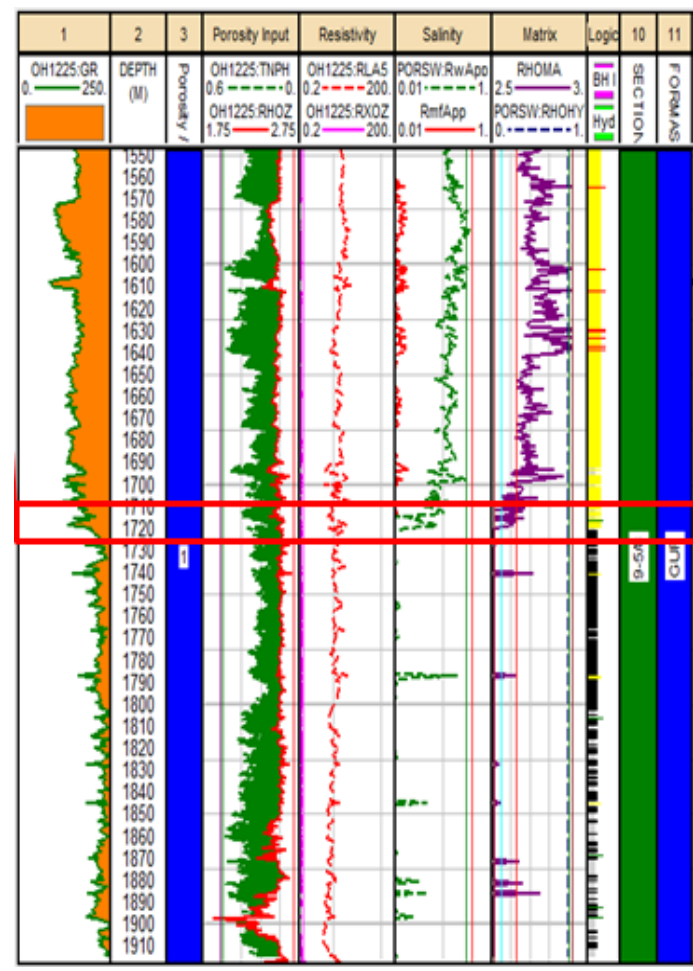

Gambar 6. Indikasi Low Resistivity Reservoir Zona 2 


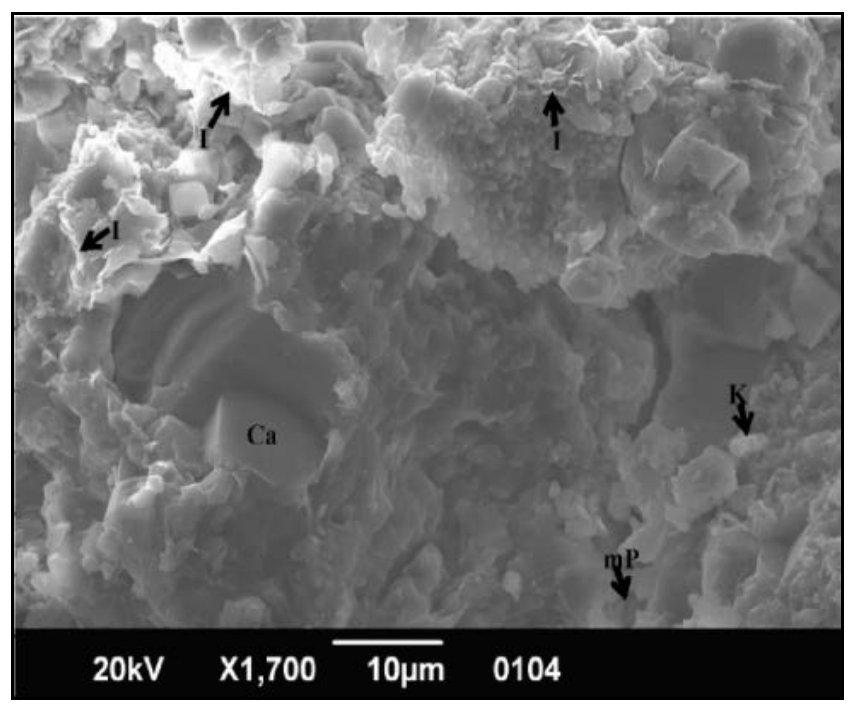

Gambar 7. Data SEM Zona 2

\begin{tabular}{|c|c|c|c|}
\hline Other mineral [58\%] & $54 \%$ & Pyrite & $2 \%$ \\
\hline Quatz & $1 \%$ & Plagioclase & $1 \%$ \\
\hline K-feldspar & $0 \%$ & Gypsum & $0 \%$ \\
\hline Zeolite [Laumontite] & $26 \%$ & Dolomite & $6 \%$ \\
\hline Carbonate minerals [3\%] & $0 \%$ & & \\
\hline Calcite & & \\
\hline Siderite & $0 \%$ & Illite & $5 \%$ \\
\hline Clay minerals [28\%] & $5 \%$ & Chlorite & $0 \%$ \\
\hline Smectite & & & \\
\hline Kaolinite &
\end{tabular}

Gambar 8. Data XRD Zona 2

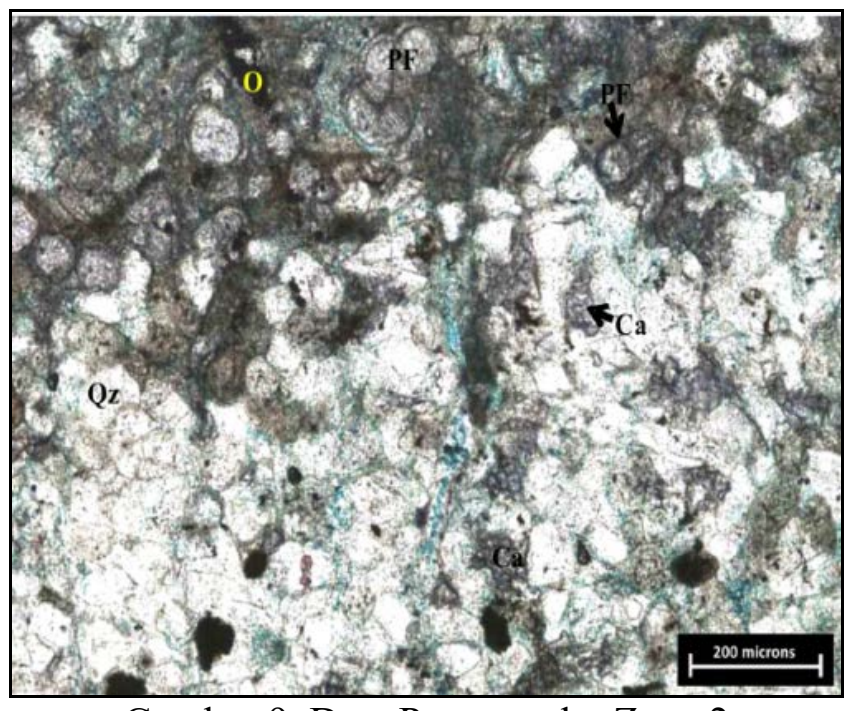

Gambar 9. Data Petrography Zona 2 


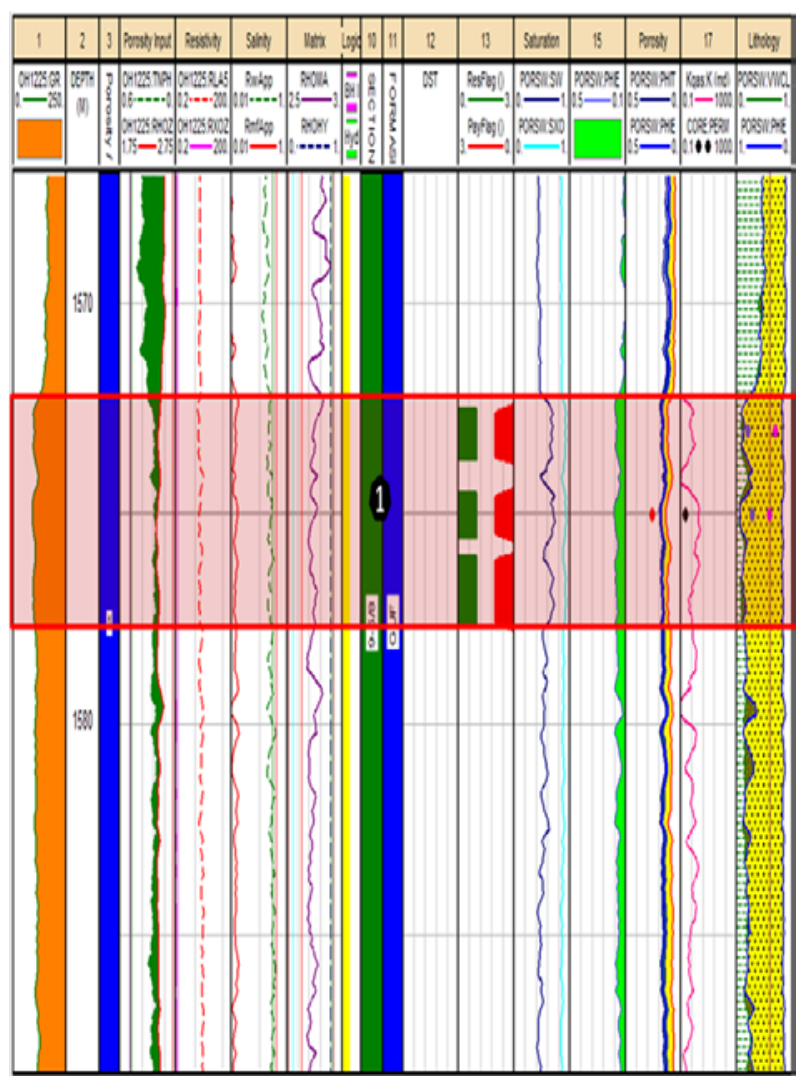

Gambar 10. Zona Low Resistivity Reservoir

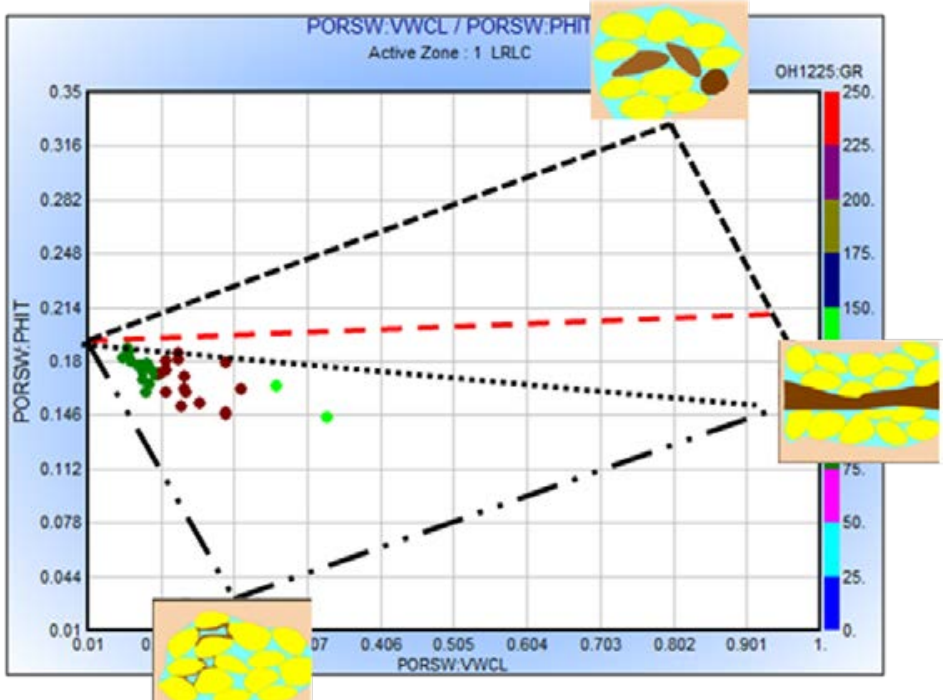

Gambar 11. Crossplot VWCL/ PHIT 


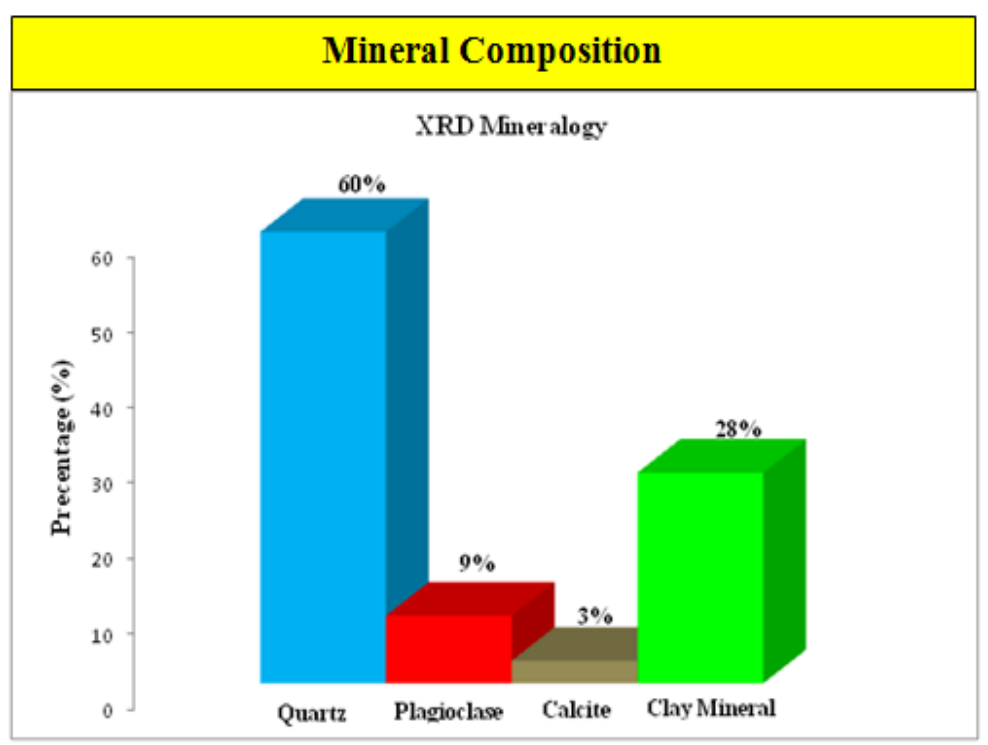

Gambar 12. Mineral Composition

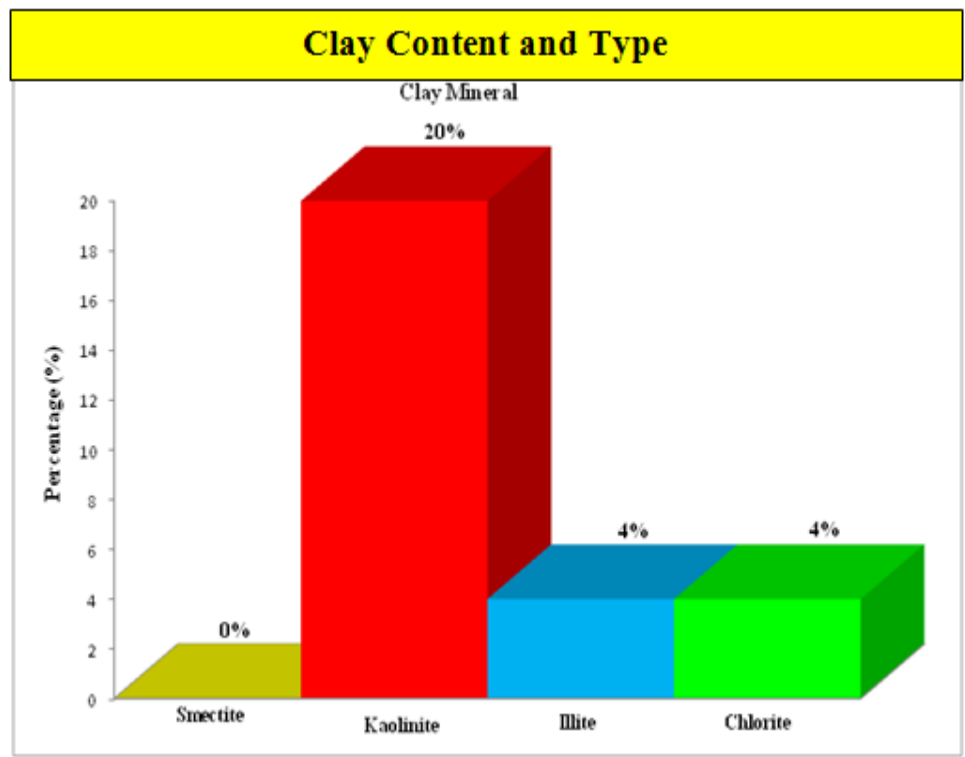

Gambar 13. Clay Content and Type 